talenta

\title{
ASSOCIATION OF E-CADHERIN EXPRESSION TO CLINICAL STAGE OF NASOPHARYNGEAL CARCINOMA
}

\author{
Felicia Melani Triastuti ${ }^{1,3 *}$, Rizalina A. Asnir ${ }^{1,3}$, Ashri Yudhistira ${ }^{1,3}$, Sutoyo Eliandy ${ }^{2}$ \\ ${ }^{I}$ Department of Otorhinolaryngology Head and Neck Medical Faculty of University of Sumatera Utara/H. Adam Malik Medan General Hospital \\ ${ }^{2}$ Pathological Anatomy Unit Installation H. Adam Malik Medan General Hospital \\ ${ }^{3}$ Center of Excellence Nasopharyngeal Carcinoma, Universitas Sumatera Utara, Indonesia
}

\section{Abstract}

Introduction: Nasopharyngeal carcinoma (NPC) has a high incidence rate in southern China and Southeast Asia and a high rate of metastasis in head and neck cancer. NPC is a squamous cell carcinoma that grows from the surface of the lateral wall of the nasopharynx. E-cadherin is known as a tumor suppressor protein and the loss of this expression in tumor cells is related to epithelial-mesenchymal transition that occurs during tumo development and metastasis.

Objective: To determine the relationship between E-cadherin expression and clinical stage in patients with nasopharyngeal carcinoma.

Methods: An analytical study with a cross-sectional study design, the number of samples was 30 patients with NPC who underwent immunohistochemical examination on KNF paraffin block.

Result: Overexpression of E-cadherin was found in T1 and T2 of 15 subjects (100\%). The overexpression of Ecadherin was found in lymph node N2 and N3 of 19 subjects (95\%). The overexpression of E-cadherin was found in the histopathological type of Non-Keratinizing Squamous Cell Carcinoma of 24 subjects (96\%). The overexpression of E-cadherin was found at an advanced stage of 26 subjects (100\%).

Conclusion: No significant association was found between E-cadherin expression and tumor size $(\mathrm{p}=1.000)$, lymph node metastasis $(\mathrm{p}=1.000)$, histopathological type $(\mathrm{p}=1.000)$ and tumor stage $(\mathrm{p}=0.133)$
\end{abstract}

\section{Article Info}

Keywords:

Nasopharyngeal carcinoma, E-cadherin

immunohistochemistry

\section{*Corresponding author:}

Address: Jalan Eka Surya Gang. Sidodadi No. 2, Johor, Medan, Sumatera Utara, Indonesia, 20144.

e-mail: feliciamelani89@gmail.com

\section{INTRODUCTION}

Nasopharyngeal carcinoma (NPC) has a high incidence rate in southern China and Southeast Asia and a high rate of metastasis in head and neck cancer [1]. The close relationship between Epstein-Barr virus infection and NPC shows that NPC grows as cancer associated with inflammation [1].

NPC is a squamous cell carcinoma that grows from the surface of the lateral wall of the nasopharynx [2]. In some countries in the world including the United States of America, the NPC is relatively rare and has an incidence of $<1$ case per 100.000 population every year. Among Asian populations, especially in South China, the NPC is in the rank of 11 malignancies that often occur with an average incidence rate almost 25 cases per 100.000 population [3].

NPC is one of the most common cancers in South China and Southeast Asia [4]. According to the WHO (World Health Organization), the most common type of histology is undifferentiated carcinoma [5]. A high incidence occurs in several regions of South China, especially in Guangzhou province, with an incidence of around $30-80$ per 100.000 population per year [6] causing serious health problems [4]. Medium incidents occurred in Southeast Asia including Singapore (15 per 100.000), Malaysia (9.7 per 100.000), Vietnam (7.5 per 100.000), Taiwan (7 per 100.000) and the Philippines (6.4 per 100.000). This tendency also applies in Africa, including Kenya (5.4 per 100.000) and Algeria, Morocco, and Tunisia (5.1 per 100.000) [7].

NPC with more than 13,000 new cases annually is one of the most common types of malignancy in Indonesia, especially in men and is associated with a high mortality rate [8]. The incidence of NPC in Indonesia is estimated at 6.2 per 100.000 or around 12.000 new cases occur each year [7]

E-cadherin is known as tumor suppressor protein and the loss of this expression in tumor cells is related to epithelial-mesenchymal transition (EMT) that occurs during tumor development and metastasis process [9, 10]. As a result of the loss of adhesion cells mediated by E-cadherin it causes cells to separate from the primary tumor, attack the surrounding tissue and migrate to distant sites [10].

In most cases, in the NPC tissue that has high E-cadherin expression and the cells are less invasive and metastatic then it will lead to a good prognosis. Reduced expression of E-cadherin often shows a poor clinical prognosis in patients with cancer [11]. In many types of cancer including NPC, the expression E-cadherin was found to be decreased. Thus it was concluded that the decrease in E-cadherin might play a role in tumor development and metastasis process [12]. This study aims to determine the relationship between E-cadherin expression to the clinical stage of NPC.

\section{MATERIAL AND METHODS}

This study is an analytical study with a cross-sectional study design. This research was conducted in the Division of Oncology-Head Neck Surgery Department of Otorhinolaryngology-Head-and-Neck Medical Faculty of University of Sumatera Utara/H. Adam Malik Medan General Hospital and Pathological Anatomy Unit Installation H. Adam Malik Medan General Hospital. The study conducted in May-November 2018.

The population of this study was patients diagnosed with NPC based on history taking, physical examination, radiology examination and histopathological biopsy results treated at the Division of Oncology-Head Neck Surgery of Department of Otorhinolaryngology-Head-and-Neck Medical Faculty of University of Sumatera Utara/ H. Adam Malik Medan General Hospital.

The sample of this study was patients diagnosed with NPC based on the results of histopathological examination with a sample calculation obtained 30 samples. The inclusion criteria of this study were patients diagnosed with NPC based on histopathological examination results who had never received treatment with radiotherapy, chemotherapy or a combination of both. Exclusion criteria are missing or damaged paraffin blocks and incomplete patient medical records. The research sample was taken by a non-probability sampling method by consecutive sampling.

Preparation after cutting tissue (preparations/slides): preparations are heated in high microwave level for 5 minutes. Furthermore, the preparations were deparaffinated with xylol I - II - III respectively for 5 minutes, wash in running water for 5 minutes and blocking with endogenous peroxidase $(0.5 \% \mathrm{H} 2 \mathrm{O} 2$ in methanol) for 30 minutes. Next wash with running water for 5 minutes. Give tris EDTA pretreatment in a microwave: Cook I: high power 
level for 5 minutes. Cook II: medium power level for 5 minutes. Then it is cooled for about 45 minutes. Wash with PBS pH 7.4, then limit tissue with Pap-Pen. Blocking non-specific activity with normal serum for $20^{\prime}$. Incubate preparations with E-cadherin primary antibodies for one night at $4{ }^{\circ} \mathrm{C}$ (in the refrigerator). Wash with PBS pH7.4. Then incubate with Envision for 30 minutes. Wash with PBS pH 7.4 - Twin 20 then PBS for 5 minutes each. Furthermore, the preparation was given chromogen to be colored with DAB (Diamino Benzidine) for approximately 5 minutes. Wash with running water. Counterstain with Hematoxylin Lilie Mayers. Wash with running water. Saturated Lithium Carbonate (5\% in aquadest for 1-2 minutes). Wash with running water. Next do dehydration with multilevel alcohol $(80 \%$ alcohol, 96\% alcohol, absolute alcohol I and II each for 5 minutes). Clearing with xylol I, II, III for 5 minutes each. Cover with Entellan and cover glass. Can be read directly. E-cadherin was assessed on the basis of the percentage of immunopositive cells as follows: $0.0 \%$; +1 , less than $10 \% ;+2,10-50 \%$; and +3 , greater than $50 \%$. Staining intensity was evaluated as weak $(+1)$, moderate $(+2)$, or strong $(+3)$. When the sum of the proportion score and intensity score was more than 4 (range $0-6$ ). The evaluation was carried out by 2 pathologists without knowing the patient's clinical data. For the final score immunoreactive scores were used, with assessment: no overexpression of E-cadherin, immunoreactive score 0-3; E-cadherin overexpression, immunoreactive score 4-6 [13].

\section{RESULT}

The characteristics of the subjects included age, gender, histopathological type, primary tumor size, enlargement of the neck lymph nodes and the disease stages listed in table 1.

Table 1. Characteristics of Sample

\begin{tabular}{lrr}
\hline Characteristic & $\mathbf{n}=\mathbf{3 0}$ & $\mathbf{\%}$ \\
\hline Age & 2 & \\
$<20$ & 3 & 6.7 \\
$20-29$ & 4 & 10 \\
$30-39$ & 6 & 13.3 \\
$40-49$ & 10 & 20 \\
$50-59$ & 3 & 33.3 \\
$60-69$ & 2 & 10 \\
$\geq 70$ & 22 & 6.7 \\
\hline Gender & 8 & 73.3 \\
Male & & 26.6 \\
Female & 0 & 0 \\
Histopathological Type & 25 & 83.3 \\
Keratinizing squamous cell carcinoma & 5 & 16.7 \\
Non keratinizing squamous cell carcinoma & & \\
Undifferentiated carcinoma & 5 & 16.7 \\
Primary tumor size & 10 & 33.3 \\
T1 & 9 & 30 \\
T2 & 6 & 20 \\
T3 & & \\
T4 & 2 & 6.7 \\
Cervical lymph node enlargement & 8 & 26.7 \\
N0 & 7 & 23.3 \\
N1 & 13 & 43.3 \\
N2 & & \\
N3 & 0 & 0 \\
Stage & 4 & 13.3 \\
I & 11 & 36.7 \\
II & 15 & 50 \\
III & & \\
IV & & \\
\hline & & \\
\hline
\end{tabular}

This study was followed by 30 people who met the inclusion criteria. The majority of the subjects were male as many as 22 people $(73.3 \%)$, with the highest age in the 50-59 year age group as many as 10 people (33.3\%). The average age of the study subjects was 46.67 years with the youngest age 18 years and the oldest 73 years.

From the results of the histopathological examination, it appears that the Non-Keratinizing histopathology type is the most common histopathological type in this study as many as 25 people $(83.3 \%)$. The size of the primary tumor found in this study was T2 as many as 10 subjects (33.3\%), at least T1, 5 subjects $(16.7 \%)$. Most lymph node enlargement was $\mathrm{N} 3$ as many as 13 subjects $(43.3 \%)$, at least N0 were 2 subjects $(6.7 \%)$. The most common disease stage was stage 4 , which was 15 patients $(50 \%)$ and no patients with stage 1 were found.

Table 2. E-Cadherin Expression based on Tumor Size

\begin{tabular}{cccc}
\hline Tumor size & \multicolumn{3}{c}{ E-Cadherin Expression } \\
\cline { 2 - 4 } & Overexpression & No overexpression & P \\
\hline T3 and T4 & $14(93.3)$ & $1(6.7)$ & 1.000 \\
T1 and T2 & $15(100)$ & 0 & \\
\hline
\end{tabular}

From 15 subjects with tumor size T3 and T4, there were 14 people $(93.3 \%)$ who showed overexpression of E-cadherin. Meanwhile, NPC patients with tumor size T1 and T2 all showed over-expression of E-cadherin. Using the Fischer's Exact test, it was found that there was no significant association between the size of the nasopharyngeal tumor and E-cadherin expression $(p=1.000)$

Table 3. E-Cadherin Expression based on Lymph Node Involvement

\begin{tabular}{|c|c|c|c|}
\hline \multirow{2}{*}{$\begin{array}{l}\text { Involvement of } \\
\text { lymph node }\end{array}$} & \multicolumn{2}{|c|}{ E-Cadherin Expression } & \multirow{2}{*}{$\mathbf{P}$} \\
\hline & Overexpression & No overexpression & \\
\hline $\mathrm{N} 2$ and N3 & $19(95)$ & $1(5)$ & 1.000 \\
\hline N0 and N1 & $10(100)$ & 0 & \\
\hline
\end{tabular}

From 20 subjects with lymph node involvement N2 and N3, there were 19 subjects $(95 \%)$ who showed overexpression. Meanwhile, subjects with lymph node involvement N0 and N1 all showed over-expression of E-cadherin. Using the Fischer exact test, it was found that no significant association was found between the number of lymph node involvement in the nasopharyngeal tumor and the expression of E-cadherin $(\mathrm{p}=1.000)$

Table 4. E-Cadherin Expression based on Histopathology Type

\begin{tabular}{|c|c|c|c|}
\hline \multirow{2}{*}{ Histopathology Type } & \multicolumn{2}{|c|}{ E-Cadherin Expression } & \multirow[t]{2}{*}{$\mathbf{P}$} \\
\hline & Overexpression & No overexpression & \\
\hline Non Keratinizing & $24(96)$ & $1(4)$ & 1.000 \\
\hline Undifferentiated $\mathrm{Ca}$ & $5(100)$ & 0 & \\
\hline
\end{tabular}

From 25 subjects with Non-Keratinizing NPC, there were 24 people $(96 \%)$ who showed overexpression. Meanwhile, the subjects of the NPC with the Undifferentiated Carcinoma type all showed over-expression of E-cadherin. Using the Fischer's Exact test, it was found that no significant association was found between the histopathological type of nasopharyngeal tumor and $\mathrm{E}$ cadherin expression $(\mathrm{p}=1.000)$.

Table 5. E-Cadherin Expression based on Clinical Stage

\begin{tabular}{lccc}
\hline \multirow{2}{*}{ Stage } & \multicolumn{2}{c}{ E-Cadherin Expression } & \multirow{2}{*}{$\mathbf{P}$} \\
\cline { 2 - 3 } & Overexpression & No overexpression & \multirow{2}{*}{0.133} \\
Early & $3(75)$ & $1(25)$ & \\
Advanced & $26(100)$ & 0 & \\
\hline
\end{tabular}

From 29 samples with E-cadherin overexpression there were 26 subjects $(100 \%)$ with advanced stages. All subjects that did not show overexpression amounted to 1 person at an advanced stage. Using the Fischer's Exact test, it was found that no significant association was found between the stage of the nasopharyngeal tumor and E-cadherin expression $(\mathrm{p}=0.133)$.

\section{DISCUSSION}

The most age group is the age group 50-59 which is as many as 10 subjects $(33.3 \%)$ seen in Table 4.1. Similar studies also reported similar results, as in Susilo's study (2018) which reported the highest proportion of age is in the 41-60 year age group as well as other studies that reported the most NPC patients is in the 36-60 year age group [14-16].

In this study, the comparison of subjects with male and female gender was 2.7:1 (Table 1). Some previous studies that have been conducted both in Medan and other countries also show that male NPC sufferers outnumber women with an average ratio of 2-3:1 [17-20].

The incidence of nasopharyngeal cancer in men is 2 to 3 times higher than women. This difference between men and women may be caused by differences in habits and lifestyle (for example tobacco consumption) or biological differences. There is a hypothesis about the role of estrogen in the incidence of nasopharyngeal carcinoma, but the relationship between sex hormone exposure and the risk of NPC in humans has never been studied epidemiologically [21].

The most common histopathological type found in this study was non-keratinizing squamous cell carcinoma as many as 25 subjects $(83.3 \%)$ (Table 1). Similar research conducted at M. Djamil Padang General Hospital also showed the highest number of nonkeratinizing squamous cell carcinoma types with a percentage of $75 \%$ [22]. However, the different results reported by extensive studies examining the epidemiology of NPC in Indonesia report the most cases in Indonesia are WHO type III (undifferentiated carcinoma), with a percentage of $85 \%$ [7]. Research in Dr. Cipto Mangunkusumo Hospital also reported the highest percentage of histopathological type of NPC was WHO type III (75.4\%) [23].

In this study, the largest size of the primary tumor found was T2 (33.3\%). The most lymph nodes enlargement found was N3 (43.3\%) and the most common stage was stage IV $(50 \%)$. In Indonesia, the highest 
proportion of NPC patients is T4 for tumor size, N3 for neck lymph nodes enlargement and advanced clinical stages [7]. At Dr. Cipto Mangunkusumo Hospital, the most common patient stages were stadium 4A, 4B and 4.

From 29 subjects with E-cadherin overexpression there were 15 subjects $(100 \%)$ with tumor size T1 and T2. No significant association was found between E-cadherin expression and tumor size $(\mathrm{p}=1.000)$ (Table 2). From the results of the study, there were 19 subjects $(95 \%)$ who showed E-cadherin overexpression with the lymph node involvement of N2 and N3. No significant association was found between E-cadherin expression and lymph node metastasis $(\mathrm{p}=1.000)($ Table 3$)$. Of the 25 subjects with Non-Keratinizing NPC there were 24 people $(96 \%)$ who showed E-cadherin overexpression. There was no significant association between histopathological type of nasopharyngeal tumor and $\mathrm{E}$ cadherin expression $(\mathrm{p}=1.000)$ (Table 4). Of the 29 subjects with E-cadherin overexpression there were 26 subjects $(100 \%)$ with advanced stages. There was no significant association between E-cadherin expression and tumor stage $(\mathrm{p}=0.133)$ (Table 5).

No significant association found between E-cadherin expression and tumor growth, lymph node metastasis, histopathology type, and tumor stage can be explained as follows:

The process by which tumor cells leave the primary location and reach the distant organ to form a new tumor is called metastasis, which is the main pathological feature of cancer. During this process, cancer cells originating from the epithelium gradually lose their epithelial characteristics and obtain a mesenchymal phenotype; this process is called the epithelial-tomesenchymal (epithelial-to-mesenchymal/EMT) transition. The molecular change in intercellular adhesion is the first step in EMT in cancer cells, and a decrease in the regulation of E-cadherin expression is a feature of this process. Because E-cadherin mediates cell adhesion through $\mathrm{Ca}^{2+}$ dependent homophilic interactions, downregulation of E-cadherin will reduce cell adhesion. Previous data showed that E-cadherin was a tumor suppressor. However, recent studies have confirmed that E-cadherin suppresses and promotes cancer development [11].

In NPC with initial metastasis, there will be downregulation of E-cadherin so that the expression of E-cadherin is lower than NPC without metastasis. In addition to downregulation, proteolysis process also occurs [24].

Down-regulation of E-cadherin will facilitate tumor cells to separate from the primary tumor. Although downregulation E-cadherin is needed for an invasion, in some cases of malignancy, E-cadherin is maintained. E-cadherin consists of many extracellular domains, transmembrane segments, and cytoplasmic domains. E-cadherin can undergo proteolysis and release protein membrane fragments called ectodomain shedding [25, 26].

E-cadherin undergoes division in certain parts. This division produces fragments that have different oncogenic properties. Mature E-cadherin 120$\mathrm{kDa}$ will be divided into an $80-\mathrm{kDa} \mathrm{N}$-terminal extracellular fragment by $\alpha$ secretase and 38-kDa C-terminal fragment [11]. This ectodomain fragment is called soluble E-cadherin/sE-cad which will be released from the plasma membrane and spread diffusely in the extracellular area and a part enter the blood vessels as a paracrine/autocrine signaling molecule. While C-terminal intracellular fragments (E-cad/CTF1) are retained in the plasma membrane until division arises on the intracellular side by $\gamma$-secretase [27]. This will damage the adherent junction and release the intracellular fragments $33-\mathrm{kDa}$ (E-cad/CTF2) into the cytosol and function as intracellular signaling. Ecadherin fragments are an oncogene. sE-cad reduces the amount of fulllength E-cadherin on the plasma membrane, this will damage the existing adherens junction and cause the cell to separate between one cell and another cell. This will make it easier for cells to invade [28]. Also, sE-cad activates MMP expression to improve the decay of sE-cad (ectodomain shedding) and activate EGFR pathway [29]. E-cad/CTF2 activates the Wnt/ $\beta$-catenin pathway signal [2].

The proteolysis process of E-cadherin in early NPC metastases was not as high as in advanced metastatic NPC so that the E-cadherin fragments produced were not as many as E-cadherin fragments produced in proteolysis process of E-cadherin in advanced NPC metastatic. Along with the development of the tumor, the proteolysis process will increase. This results in increased E-cadherin fragments. Both E-cadherin and full-length E-cadherin fragments will be smeared on scavenging with E-cadherin antibodies so that the expression of E-cadherin in advanced NPC metastatic is further higher than that of E-cadherin in early metastatic NPC [24].

This is in accordance with previous studies which found that E-cadherin expression in the NPC group of advanced metastases was significantly higher than the early NPC metastatic group $(\alpha=0.05, \mathrm{p}<0.05)$. The mean
E-cadherin expression in early metastatic NPC (36.4\%) was lower than the mean expression of E-cadherin in advanced NPC metastases. This means that there is a relationship between tumor progression or the degree of metastasis and E-cadherin expression in NPC, where the higher the degree of NPC metastatic, the higher the expression of E-cadherin in NPC cells [24].

There is plenty of evidence that invasive and metastatic cancers maintain high levels of E-cadherin expression [11]. About 55\% of ductal carcinoma of the breast expresses high E-cadherin, and in $45 \%$ of other patients, E-cadherin expression can also be observed; even in invasive lobular carcinoma, E-cadherin expression is present in up to $12 \%$ of patients [11]. Similarly, high E-cadherin expression is positively correlated with invasive growth and infiltration of prostate cancer cells [30]. Besides, other studies have found that E-cadherin is highly expressed in glioma cells and is positively correlated with poor prognosis in patients with glioblastoma [31]. Other researchers observed abnormal E-cadherin expression in human ovarian cancer. The researchers examined specimens from 37 ovarian cancer cases, which $\sim 86.5 \%$ had high E-cadherin expression, and found that high E-cadherin expression promoted malignant transformation of ovarian epithelial cells. Together, these results suggest that high E-cadherin expression may not inhibit cancer development; but E-cadherin can also encourage metastasis [11].

Wilmanns, et al. found that comparison with 6 healthy volunteers $(3.476 \mathrm{ng} / \mathrm{ml})$, the concentration of $\mathrm{sE}$-cad was significantly higher in 36 patients with colorectal cancer $(5.495 \mathrm{ng} / \mathrm{ml})$. This concentration is strongly related to the tumor size as well as local expansion or spread, as well as the highest concentration in patients with carcinoembryonic (CEA)-positive liver metastases. Levels of sE-cad were significantly higher in patients with stage III-IV colorectal cancer and directly indicated disease progression [11].

Other researchers found that serum sE-cad levels were significantly increased in 111 breast cancer patients and confirmed that sE-cad levels were significantly associated with tumor stage, histopathological grading, and lymph node metastasis [32].

\section{CONCLUSION}

In this study no significant association was found between E-cadherin expression and tumor size $(p=1.000)$, lymph node metastasis $(p=1.000)$, histopathological type $(\mathrm{p}=1.000)$ and tumor stage $(\mathrm{p}=0.133)$. For this reason, further research is needed to evaluate the association between E-cadherin expression to clinical progression of NPC with a larger and more sustainable sample, to obtain more reliable data on the effectiveness of E-cadherin as a marker of prognosis in nasopharyngeal carcinoma.

\section{REFERENCE}

[1] Zhang R-L, Peng L-X, Yang J-P, Zheng L-S, Xie P, Wang M-Y, et al. IL-8 Suppresses E-cadherin Expression in Nasopharyngeal Carcinoma Cells by Enhancing E-cadherin Promoter DNA Methylation. International Journal of Oncology. 2016;48(1):207-14

[2] Tulalamba W, Janvilisri T. Nasopharyngeal Carcinoma Signaling Pathway: An Update on Molecular Biomarkers. International Journal of Cell Biology. 2012;2012.

[3] Patel VJ, Chen N-W, Resto VA. Racial and Ethnic Disparities in Nasopharyngeal Cancer Survival in the United States: A SEER Study. Otolaryngology-Head and Neck Surgery. 2017;156(1):122-31.

[4] Xu L, Jiang Y, Zheng J, Xie G, Li J, Shi L, et al. Aberrant Expression of $\beta$-catenin and E-cadherin is Correlated with Poor Prognosis of Nasopharyngeal Cancer. Human Pathology. 2013;44(7):1357-64.

[5] Cao X, He L-R, Xie F-Y, Chen Y-F, Wen Z-S. Factors Determining the Survival of Nasopharyngeal Carcinoma with Lung Metastasis Alone: Does Combined Modality Treatment Benefit? BMC Cancer. 2011;11(1):370.

[6] Zhao Y, Wang Y, Zeng S, Hu X. LMP1 Expression is Positively Associated with Metastasis of Nasopharyngeal Carcinoma: Evidence from A Meta-analysis. Journal of Clinical Pathology. 2012;65(1):41-5.

[7] Adham M, Kurniawan AN, Muhtadi AI, Roezin A, Hermani B, Gondhowiardjo S, et al. Nasopharyngeal Carcinoma in Indonesia: Epidemiology, Incidence, Signs, and Symptoms at Presentation. Chinese Journal of Cancer. 2012;31(4):185.

[8] Fles R, Bos A, Rachmawati D, Waliyanti E, Tan I, Haryana S, et al. The Role of Indonesian Patients' Health Behaviors in Delaying The Diagnosis of Nasopharyngeal Carcinoma. BMC Public Health. 2017;17(1):510.

[9] Rodriguez FJ, Lewis-Tuffin LJ, Anastasiadis PZ. E-cadherin's Dark Side: Possible Role in Tumor Progression. Biochimica et Biophysica Acta (BBA)-Reviews on Cancer. 2012;1826(1):23-31. 
[10] Petrova YI, Schecterson L, Gumbiner BM. Roles for E-cadherin Cell Surface Regulation in Cancer. Molecular Biology of the cell. 2016;27(21):3233-44.

[11] Hu QP, Kuang JY, Yang QK, Bian XW, Yu SC. Beyond A Tumor Suppressor: Soluble E-cadherin Promotes the Progression of Cancer. International Journal of Cancer. 2016;138(12):2804-12.

[12] Galera-Ruiz H, Ríos M, González-Cámpora R, De Miguel M, Carmona M, Moreno A, et al. The Cadherin-Catenin Complex in Nasopharyngeal Carcinoma. European Archives of Oto-RhinoLaryngology. 2011;268(9):1335-41.

[13] Kato Y, Nishihara H, Mohri H, Kanno H, Kobayashi H, Kimura T, et al. Clinicopathological Evaluation of Cyclooxygenase-2 Expression in Meningioma: Immunohistochemical Analysis of 76 Cases of Low and High-Grade Meningioma. Brain Tumor Pathology. 2014;31(1):23-30.

[14] Harahap MPH. Ekspresi Vascular Endothelial Growth Factor pada Karsinoma Nasofaring. Medan. Universitas Sumatera Utara. 2009;1-99

[15] Siregar SM. Hubungan EBNA-1 dengan Karsinoma Nasofaring di RSUP H. Adam Malik Medan. Universitas Sumatera Utara. 2010;1-70

[16] Puspitasari D. Gambaran Penderita Karsinoma Nasofaring Di RSUP H. Adam Malik Medan Tahun 2006-2010. Universitas Sumatera Utara. 2011;1-55

[17] Segawa Y, Oda Y, Yamamoto H, Shiratsuchi H, Hirakawa N, Komune $\mathrm{S}$, et al. Close Correlation between CXCR4 and VEGF Expression and Their Prognostic Implications in Nasopharyngeal Carcinoma. Oncology Reports. 2009;21(5):1197-202.

[18] Taweevisit M, Keelawat S, Thorner PS. Correlation of Microvascular Density and Proliferation Index in Undifferentiated Nasopharyngeal Carcinoma. Asian Biomedicine. 2010;4(2):315-21.

[19] Turkoz FP, Celenkoglu G, Dogu GG, Kalender ME, Coskun U, Alkis N, et al. Risk Factors of Nasopharyngeal Carcinoma in Turkey-an Epidemiological Survey of the Anatolian Society of Medical Oncology. Asian Pac J Cancer Prev. 2011;12(11):3017-21.

[20] Susilo RR. Hubungan Ekspresi TNF- $\alpha$ Terhadap Stadium Klinis pada Penderita Karsinoma Nasofaring. Medan. Universitas Sumatera Utara. 2018.

[21] Salehiniya H, Mohammadian M, Mohammadian-Hafshejani A, Mahdavifar N. Nasopharyngeal Cancer in the World: Epidemiology, Incidence, Mortality and Risk Factors. World Cancer Research Journal. 2018;5(3):7.

[22] Faiza S, Rahman S, Asri AA. Karakteristik Klinis dan Patologis Karsinoma Nasofaring di Bagian THT-KL RSUP Dr. M. Djamil Padang. Jurnal Kesehatan Andalas. 2016;5(1).

[23] Jayalie VF, Paramitha MS, Jessica J, Liu CA, Ramadianto AS, Trimartani T, et al. Profile of Nasopharyngeal Carcinoma in Dr. Cipto Mangunkusumo National Hospital, 2010. eJournal Kedokteran Indonesia. 2017:156-62.

[24] Astuti AY, Sandhika W. Ekspresi E-Cadherin dan MMP-9 pada Karsinoma Nasofaring Tanpa Metastasis, dengan Metastasis Awal dan Metastasis Lanjut Kelenjar Getah Bening. Majalah Patologi Indonesia. 2016;25(2).

[25] David JM, Rajasekaran AK. Dishonorable Discharge: The Oncogenic Roles of Cleaved E-Cadherin Fragments. Cancer Research. 2012;72(12):2917-23.

[26] Konze SA, van Diepen L, Schröder A, Olmer R, Möller H, Pich A, et al. Cleavage of E-cadherin and $\beta$-catenin by Calpain Affects Wnt Signaling and Spheroid Formation in Suspension Cultures of Human Pluripotent Stem Cells. Molecular \& Cellular Proteomics. 2014;13(4):990-1007.

[27] Ferber EC, Kajita M, Wadlow A, Tobiansky L, Niessen C, Ariga H, et al. A Role for The Cleaved Cytoplasmic Domain of E-Cadherin in The Nucleus. Journal of Biological Chemistry. 2008;283(19):12691-700.

[28] Grabowska MM, Day ML. Soluble E-cadherin: More Than A Symptom of Disease. Frontiers in Bioscience (Landmark Edition). 2012;17:1948.

[29] Inge LJ, Barwe SP, D'ambrosio J, Gopal J, Lu K, Ryazantsev S, et al. Soluble E-cadherin Promotes Cell Survival by Activating Epidermal Growth Factor Receptor. Experimental Cell Research. 2011;317(6):838-48.

[30] Putzke AP, Ventura AP, Bailey AM, Akture C, Opoku-Ansah J, Çeliktaş M, et al. Metastatic Progression of Prostate Cancer and ECadherin: Regulation by Zeb1 and Src Family Kinases. The American Journal of Pathology. 2011;179(1):400-10.

[31] Lewis-Tuffin LJ, Rodriguez F, Giannini C, Scheithauer B, Necela BM, Sarkaria JN, et al. Misregulated E-cadherin Expression Associated with An Aggressive Brain Tumor Phenotype. PloS One. 2010;5(10):e13665.

[32] Wang T, Chu Z, Lin H, Jiang J, Zhou X, Liang X. Galectin-3 Contributes to Cisplatin-Induced Myeloid Derived Suppressor Cells (Mdscs) Recruitment in Lewis Lung Cancer-Bearing Mice. Molecular Biology Reports. 2014;41(6):4069-76. 